\title{
A AUTONOMIA UNIVERSITÁRIA E OS PROGRAMAS DE RESIDÊNCIA MÉDICA NO BRASIL: OS LIMITES DA LEI DO “MAIS MÉDICOS”
}

\author{
UNIVERSITY AUTONOMY AND MEDICAL RESIDENCY IN BRAZIL: THE CONSTITUTIONAL
}

LIMITS OF THE "MORE DOCTORS ACT"

Nina Beatriz Stocco Ranieri*

\begin{abstract}
Resumo:
$\mathrm{O}$ artigo analisa as prerrogativas da autonomia universitária em face da polêmica Lei n. 12.871/2013, a chamada lei do "Mais Médicos", destinada a formar recursos humanos na área médica para o Sistema Único de Saúde brasileiro - SUS, previsto no art. 198 da Constituição Federal. A problemática propicia uma visão ampla sobre a matéria constitucional e legal relacionada à repartição de competências educacionais, à composição dos sistemas de ensino, à autonomia universitária e à atuação de universidades públicas na residência médica. Os argumentos apresentados sustentam que: os programas de residência médica constituem modalidade de cursos de especialização, submetidos às normas constitucionais e legais da educação nacional, com as peculiaridades que lhes confere a Lei n. 6.932/1981. A Lei do "Mais Médicos" não altera a natureza acadêmica desses programas; o regime jurídico dos programas de residência médica é de direito público, conforme previsto na Lei n. 6.932/1981 e extraído da Lei de Diretrizes e Bases da Educação Nacional (LDB), é conformado pelo princípio da legalidade e pelos princípios constitucionais educacionais, entre estes o da autonomia universitária; a autonomia universitária constitui fundamento suficiente para que as universidades públicas deliberem sobre os aspectos acadêmicos dos programas de residência médica que oferece, em toda a sua extensão, de acordo com a Constituição Federal e a LDB.
\end{abstract}

Palavras-chave: Autonomia universitária. Residência Médica. Lei n. 12.871/2013. Lei do "Mais Médicos".

\begin{abstract}
:
The paper analyzes the prerogatives of university autonomy vis à vis Law No. $12,871 / 2013$, the so called "More Doctors Act", specially enacted to provide medical training for human resources in the Brazilian health care system - SUS, established by the article 198 of the Federal Constitution. The paper presents an overview of the constitutional and legal matters relating to the State educational responsibilities, the educational system features, the university autonomy and the role of public universities in medical training. The author states that the medical residency is a form of specialization, subject to constitutional and legal norms of national education; the legal status of medical residency is governed by public law; university autonomy is sufficient ground for public universities to deliberate on academic aspects of medical residency programs it offers, in all its length, according
\end{abstract}

Professora Associada do Departamento de Direito do Estado da Faculdade de Direito da Universidade de São Paulo. Coordenadora da Cátedra UNESCO de Direito à Educação da Faculdade de Direito da Universidade de São Paulo. 
to the Federal Constitution and the National Education Act (Law No. 9,394/1996).

Keywords: University autonomy. Medical Residency. Law No. 12,871/13. "More Doctors Act".

Introdução

O presente artigo analisa as prerrogativas da autonomia universitária em face da polêmica Lei n. 12.871/2013, a chamada lei do "Mais Médicos", destinada a formar recursos humanos na área médica para o Sistema Único de Saúde brasileiro - SUS (rede pública regionalizada e hierarquizada, de acesso universal e gratuito, prevista no art. 198 da Constituição Federal - CF).

Para tanto, a Lei do "Mais Médicos" pretende reordenar a oferta de cursos de Medicina e de vagas para residência médica, priorizando regiões de saúde com menor relação de vagas e médicos por habitante e com estrutura de serviços de saúde em condições de ofertar campo de prática suficiente e de qualidade para os alunos. O objetivo é promover a integração do ensino ao SUS, inclusive por meio de intercâmbio internacional (como se verificou em relação à contração de médicos cubanos no ano de 2014, mediante acordo entre o Brasil e Cuba), entre outras medidas.

O problema é que a lei incorre em inconstitucionalidades no que diz respeito à autonomia didática, científica e administrativa das universidades, a saber:

- obrigação de oferta anual de vagas de residência médica em número equivalente ao número de egressos dos cursos de graduação em Medicina do ano anterior, a ser implantada progressivamente até 31 de dezembro de 2018 (art. $5^{\circ}$.);

- atribuição de bonificação adicional de $10 \%$ (dez por cento) na nota de todas as fases ou da fase única do processo de seleção pública dos Programas de Residência Médica para o candidato que tiver participado do Programa de Valorização do Profissional da Atenção Básica (PROVAB), (art. 22).

Além disso, as Diretrizes Curriculares para o Curso de Medicina - DCN, estabelecidas pelo Governo federal e de observância nacional, instituiu avaliação obrigatória para o estudante do Curso de Graduação em Medicina, considerados os seus resultados como parte do processo de classificação para os exames dos programas de Residência Médica, credenciados pela Comissão Nacional de Residência Médica (CNRM), sendo sua realização de âmbito nacional (Resolução Conselho Nacional de Educação n. 3/2014, art. 36).

Embora a problemática envolva particularismos próprios ao campo da saúde, sua abordagem propicia uma visão ampla sobre a matéria constitucional e legal relacionada à repartição de competências educacionais, à composição dos sistemas de 
ensino, à autonomia universitária e à atuação de universidades públicas. Basicamente, os argumentos aqui expostos demonstram que:

a) No Brasil, os programas de residência médica constituem modalidade de cursos de especialização, submetidos às normas constitucionais e legais da educação nacional, com as peculiaridades que lhes confere a Lei n. 6.932/1981. A Lei do "Mais Médicos" não altera a natureza acadêmica desses programas.

b) O regime jurídico dos programas de residência médica é de direito público, conforme previsto na Lei n. 6.932/1981 e extraído da Lei de Diretrizes e Bases da Educação Nacional (LDB), é conformado pelo princípio da legalidade e pelos princípios constitucionais educacionais, entre estes o da autonomia universitária.

c) A autonomia universitária constitui fundamento suficiente para que as universidades públicas deliberem sobre os aspectos acadêmicos dos programas de residência médica que oferece, em toda a sua extensão, de acordo com a Constituição Federal (CF) e a LDB.

É o que se passa a demonstrar, na seguinte conformidade: 1. As competências da União e dos Estados na educação superior e, particularmente, nos cursos na área médica; 2. A natureza jurídica do Programa "Mais Médicos"; 3. A autonomia universitária e as novas regras da residência médica; e Conclusões.

1. As competências da União e dos Estados na educação superior e, particularmente, nos cursos na área médica

1. A repartição de encargos e competências no campo da educação promovida pela Constituição Federal de 1988 promove descentralização vertical e hierarquizada.

No plano dos encargos, observa-se certa simetria entre as atribuições dos entes federados, tendo sido reservados à União poderes para promover a coordenação nacional das atividades. A partir da ênfase à competência genérica comum (prevista nos arts. 205, 206 e 208 da CF) $)^{1}$ é que se dá a indicação dos níveis de ensino de atuação

\footnotetext{
1 “Art. 205. A educação, direito de todos e dever do Estado e da família, será promovida e incentivada com a colaboração da sociedade, visando ao pleno desenvolvimento da pessoa, seu preparo para o exercício da cidadania e sua qualificação para o trabalho."

"Art. 206. O ensino será ministrado com base nos seguintes princípios: I - igualdade de condições para o acesso e permanência na escola; II - liberdade de aprender, ensinar, pesquisar e divulgar o pensamento, a arte e o saber; III - pluralismo de ideias e de concepções pedagógicas, e coexistência de instituições públicas e privadas de ensino; IV - gratuidade do ensino público em estabelecimentos oficiais; V - valorização dos profissionais da educação escolar, garantidos, na forma da lei, planos de carreira, com ingresso exclusivamente por concurso público de provas e títulos, aos das redes públicas; VI - gestão democrática
} 
prioritária, mas não exclusiva, para cada esfera de governo, à exceção do federal, o que reclama e evidencia a necessidade de organização dos respectivos sistemas de ensino em regime de colaboração.

À União compete elaborar e executar planos de desenvolvimento econômico e social (art. 21, IX); intervir nos Estados e no Distrito Federal, em hipótese de não aplicação, na educação, do mínimo exigido da receita resultante de impostos estaduais, na forma do art. 34, VII, "e"; exercer função redistributiva e supletiva, de forma a garantir equalização de oportunidades educacionais e padrão mínimo de qualidade do ensino, mediante assistência técnica e financeira aos Estados, Distrito Federal e Municípios, em todos os níveis de ensino (art. 211, $\S 1^{\circ}$ ); aplicar na manutenção e desenvolvimento do ensino dezoito por cento da receita resultante de impostos, no mínimo (art. 212); bem como organizar o seu sistema de ensino e o dos territórios (art. 211, § $1^{\circ}$ ), financiar as instituições de ensino público federais; autorizar e avaliar os estabelecimentos de ensino de seu sistema (art. 206, VII), inclusive os particulares (art. 209, II).

Decorre do disposto no art. $8^{\circ}$ da LDB a competência da União para coordenar toda a política nacional de educação, visando articular os diferentes níveis (básico e superior) e sistemas de ensino.

Esta previsão complementa a norma genérica dos $\S \S 2^{\circ}$ e $3^{\circ}$ do art. 211 , o que significa que, sob a coordenação da União, todos os entes políticos atuarão na educação infantil, e no ensino fundamental, médio e superior, atendida a seguinte regra: Municípios prioritariamente no ensino fundamental e na educação infantil; Estados e Distrito Federal no ensino fundamental e médio.

do ensino público, na forma da lei; VII - garantia de padrão de qualidade. VIII - piso salarial profissional nacional para os profissionais da educação escolar pública, nos termos de lei federal. Parágrafo único. A lei disporá sobre as categorias de trabalhadores considerados profissionais da educação básica e sobre a fixação de prazo para a elaboração ou adequação de seus planos de carreira, no âmbito da União, dos Estados, do Distrito Federal e dos Municípios."

“Art. 208. O dever do Estado com a educação será efetivado mediante a garantia de: I - educação básica obrigatória e gratuita dos 4 (quatro) aos 17 (dezessete) anos de idade, assegurada inclusive sua oferta gratuita para todos os que a ela não tiveram acesso na idade própria; II - progressiva universalização do ensino médio gratuito; III - atendimento educacional especializado aos portadores de deficiência, preferencialmente na rede regular de ensino; IV - educação infantil, em creche e pré-escola, às crianças até 5 (cinco) anos de idade; V - acesso aos níveis mais elevados do ensino, da pesquisa e da criação artística, segundo a capacidade de cada um; VI - oferta de ensino noturno regular, adequado às condições do educando; VII atendimento ao educando, em todas as etapas da educação básica, por meio de programas suplementares de material didático escolar, transporte, alimentação e assistência à saúde. $\S 1^{\circ} \mathrm{O}$ acesso ao ensino obrigatório e gratuito é direito público subjetivo. $\S 2^{\circ} \mathrm{O}$ não-oferecimento do ensino obrigatório pelo Poder Público, ou sua oferta irregular, importa responsabilidade da autoridade competente. $\S 3^{\circ}$ Compete ao Poder Público recensear os educandos no ensino fundamental, fazer-lhes a chamada e zelar, junto aos pais ou responsáveis, pela frequência à escola." 
Em razão de a Constituição Federal não ter indicado nenhum nível de ensino para a atuação prioritária da União, reforça-se a sua ação supletiva e redistributiva em todos os níveis.

Considerando-se o amplo escopo desta atribuição (todos os níveis de ensino), fica claro que à União compete oferecer o ensino superior à ausência do seu oferecimento pelas demais esferas de governos. Como estas devem se ocupar prioritariamente da educação básica, a competência da União, em relação ao ensino superior, é residual. Observa-se, no entanto, a prevalência da competência da União sobre os demais entes federados. Vale lembrar que no Brasil, tradicionalmente, o governo federal se ocupou com o seu oferecimento. ${ }^{2}$

Para os Estados, o Distrito Federal e Municípios, restam os encargos federativos de execução dos planos nacional e estaduais de educação, à vista do dever do Estado para com a educação (CF, art. 205), e por força dos arts. 10 e 11, da LDB. Há também os encargos de organização, manutenção e desenvolvimento dos respectivos sistemas de ensino, em relação aos quais deverá ser aplicado, no mínimo, 25\% da receita resultante de impostos (na forma do art. 212); e, no âmbito destes, a autorização e avaliação das instituições de ensino.

Se no plano dos encargos a atuação da União é definida pela via supletiva e residual, no plano das competências legislativas é expressamente indicada: reserva-se à União competência privativa para legislar sobre diretrizes e bases da educação nacional (CF, art. 22, XXIV); e competência concorrente à dos Estados e Distrito Federal para legislar sobre educação mediante normas gerais (CF, art. 24, IX).

As primeiras são exercidas exclusivamente pelo Congresso Nacional, mediante a edição (a) da lei de diretrizes e bases da educação nacional (CF, art. 22, XXIV); (b) de normas gerais de educação (CF, art. 24, IX).

As segundas, no plano federal, são exercidas por diversos agentes do Poder Executivo federal (o Presidente da República, por meio de decretos; o Ministro da Educação, por meio de resoluções, portarias etc.; o Conselho Nacional de Educação etc.), de acordo com as respectivas competências legais. Neste conjunto incluem-se: (c) coordenação da política nacional de educação, articulando os diferentes níveis e sistemas e exercendo funções normativas, redistributivas e supletivas, em relação às demais instâncias educacionais (LDB, art. $8^{\circ}, \S 1^{\circ}$ ); (d) edição de normas gerais sobre cursos de graduação e pós-graduação; (e) garantia do processo nacional de avaliação das instituições de educação superior, com a cooperação dos sistemas que tiverem responsabilidade

\footnotetext{
2 No sistema federal de ensino a maior parte das instituições que o compõem são de nível superior, à vista de que, além dos estabelecimentos públicos, todas as instituições de ensino superior particulares estão a este submetidas, cf. art. 16 da LDB.
} 
sobre este nível de ensino; (f) autorizar, reconhecer, credenciar, supervisionar e avaliar, respectivamente, os cursos das instituições de educação superior e os estabelecimentos do seu sistema de ensino (LDB, art. $9^{\circ}$, VII a IX).

As competências federais são limitadas pelas competências estaduais, devido ao princípio federativo, expresso no art. 18, da Constituição Federal: “a organização político-administrativa da República Federativa do Brasil compreende a União, os Estados, o Distrito Federal e os Municípios, todos autônomos, nos termos desta Constituição." Assim sendo, nem as normas gerais nem a lei de diretrizes e bases podem invadir a esfera própria dos Estados, nem versar sobre matéria alheia aos encargos atribuídos à União, sob pena de incompetência absoluta. $\mathrm{O}$ mesmo ocorre em relação à regulamentação definida por decreto, portarias ou resoluções.

Comparada à federal, a competência dos Estados é extremamente restrita. Figuram neste rol: (a) baixar normas complementares para seu sistema de ensino, destinadas a atender especificidades regionais (CF, art. 24, IX); (b) manter e desenvolver os órgãos e instituições dos respectivos sistemas de ensino; e (c) autorizar, reconhecer, credenciar, supervisionar e avaliar as suas instituições de ensino superior (LDB, art. 10).

2. Ocorre que, como no Brasil, tradicionalmente, o Governo federal se encarregou do oferecimento e regulamentação do ensino superior, firmou-se a crença de que o Congresso Nacional e o Ministério da Educação têm, neste campo, jurisdição sobre todo o território nacional. A crença é também alimentada pelo duplo papel do Congresso Nacional, que é simultaneamente órgão legislativo do Estado Federal (é dizer, da Nação) e da União (enquanto ente federado).

Cabem aqui algumas considerações acerca dos dois planos de incidência da legislação aprovada pelo Congresso Nacional.

No plano nacional, tanto as funções legislativas quanto as normativas, voltam-se à coordenação da política de educação e à articulação dos diversos níveis e sistemas. No plano federal, voltam-se à organização do sistema federal de ensino. Evidentemente, nem tudo o que é lei ou norma federal é lei ou norma nacional - e, portanto, não são aplicáveis aos demais sistemas de ensino - embora o inverso seja verdadeiro.

No caso da edição de normas gerais e de diretrizes e bases, todas as instâncias educacionais, de qualquer sistema de ensino, serão alcançadas. Diversamente, em se tratando de detalhamento de normas gerais, apenas as instâncias do sistema federal é que se subsumem à sua esfera de incidência. No primeiro caso, são editadas leis nacionais; no segundo, leis federais, normas parciais que obrigam apenas no âmbito do sistema de ensino da União. E, apesar de serem ambas editadas pelo Congresso Nacional, órgão legislativo da União, não são, concomitantemente, nacionais e federais. 
A competência federal para baixar normas gerais sobre os cursos de graduação e pós-graduação segue a mesma lógica: nem tudo o que é lei ou norma federal é lei ou norma nacional.

3. Desdobramento do mesmo problema é a confusão entre as normas gerais de educação e a lei de diretrizes e bases da educação. Embora sejam espécies distintas, ambas emanam do mesmo órgão legislativo, se originam por processos semelhantes, tratam de matérias análogas e têm alcance nacional.

Normas nacionais, ou "leis brasileiras", são leis indistintamente voltadas a todos os sistemas de ensino, e a todas as instituições escolares - públicas e privadas - devido ao fato de emanarem do Estado Federal, pessoa política com competências e finalidades próprias, distintas das dos entes que a compõem (União, Estados e Municípios). A norma nacional é geral, global, total. À ausência de normas gerais, os Estados exercem a capacidade legislativa plena, como expresso no art. 24, IX, e §s.

A matéria de diretrizes e bases, por sua vez, é de definição mais precisa. Não sendo apontada em função da generalidade da norma, mas em face do conteúdo que, necessariamente, deve remeter às ideias de fundamento, organização e condições de exequibilidade da educação escolar "que se desenvolve, predominantemente, por meio do ensino, em instituições próprias.” (Art. $1^{\circ}$, § $1^{\circ}$, da Lei n. 9.394/1996). Logo, quando se fala em diretrizes e bases, fala-se em estrutura, em arcabouço do ensino escolar nacional, em todos os seus níveis (educação básica e educação superior) e modalidades (ensino presencial, a distância etc.). A LDB, por ser norma fundamental, diretriz, não tem a natureza de legislação exaustiva.

4. É inevitável que sobre uma zona cinzenta na delimitação das fronteiras objetivas da norma geral e das normas diretivo-basilares, o ponto além do qual não podem ultrapassar, sob pena de ferir a competência dos demais entes federados.

É possível distinguir as normas supletivas das normas gerais, e estas das de diretrizes e bases, com esteio em critérios que levem em conta a forma e a extensão do tratamento dado à matéria: diante de uma prescrição normativa na área educacional, examina-se se ela especializa e aprofunda questões. Neste caso, não será diretriz ou base, nem tampouco norma geral, mas norma de competência estadual. Se, não especializando, estabelece princípios e fundamentos, dá-se o contingenciamento generizador, nacional, que caracteriza a norma geral.

Não é necessário que as leis que estabelecem princípios e fundamentos ou diretrizes e bases para o ensino superior sejam denominadas como "normas gerais de educação" ou de "diretrizes e bases" para que incidam sobre todos os sistemas de ensino. Ou seja, não é o nome, mas a sua natureza jurídica que determinará a incidência ou não da norma. 
Na prática, a legislação de ensino, além de excessiva, caracteriza-se pela multiplicidade e a provisoriedade das regras, e pela variabilidade das fontes (o Congresso Nacional, o Presidente da República, o Ministério da Educação, o Conselho Nacional de Educação, os Conselhos Estaduais de Educação etc.).

Tudo contribui para a falta de clareza sobre o que se aplica a quem (só o sistema federal? Todos os sistemas?) e em que momento (imediatamente após a publicação no Diário Oficial da União? Após adoção pelos respectivos Conselhos Estaduais de Ensino?). Qual o peso de cada uma dessas regras? O que deve ser atendido?

Para os cursos de medicina, o cenário é agravado pela circunstância de envolver, no plano federal, além do Congresso Nacional e do Ministério da Educação MEC, a Comissão Nacional de Residência Médica - CNRM, o Ministério da Saúde - MS, e, no plano estadual, a Secretaria da Saúde - SES.

A ordenação da formação de recursos humanos para a saúde, prevista no art. 200, III, da Constituição Federal, é competência comum da União e dos Estados, em suas respectivas áreas de atuação. A situação é análoga à da área da educação, no que diz respeito às normas gerais. União e Estados legislam concorrentemente sobre proteção e defesa da saúde (CF, art. 24, XII), não havendo hierarquia entre ambas, mas distintas esferas de incidência, que decorrem do princípio federativo e do direito constitucional brasileiros. Ademais, na esfera estadual, as Secretarias de Saúde são as gestoras do SUS, o que implica mais um nível de compartilhamento de ações.

5. É neste terreno pantanoso que se insere a problemática criada pela Lei do "Mais Médicos": seriam aplicáveis às universidades públicas estaduais, criadas e mantidas pelos estados federados, todas autônomas na forma do art. 205 da Constituição Federal, as disposições da referida lei no que tange à seleção e avaliação de alunos para a residência médica?

A resposta é negativa, pois apenas as normas da Lei n. 12.871/2013 e da Resolução CNE n. 3/2014 com natureza de regra diretivo basilar ou geral obrigariam as universidades públicas estaduais, o que não é o caso.

\section{A natureza jurídica do Programa "Mais Médicos"}

6. O Programa "Mais Médicos", instituído pela Medida Provisória n. 621, de 8/7/2013, convertida na Lei n. 12.871, de 22/10/2013, visa formar recursos humanos na área médica para o Sistema Único de Saúde - SUS.

A política pública estabelecida na lei tem por objetivos: (a) diminuir a carência de médicos nas regiões prioritárias para o SUS, a fim de reduzir as desigualdades regionais na área da saúde; (b) fortalecer a prestação de serviços de atenção básica em saúde no País; (c) aprimorar a formação médica no País e proporcionar maior experiência 
no campo de prática médica durante o processo de formação; e d) ampliar a inserção do médico em formação nas unidades de atendimento do SUS, desenvolvendo seu conhecimento sobre a realidade da saúde da população brasileira.

Para tanto, prevê-se:

Art. $2^{\circ}$. Para a consecução dos objetivos do Programa Mais Médicos, serão adotadas, entre outras, as seguintes ações:

I - reordenação da oferta de cursos de Medicina e de vagas para residência médica, priorizando regiões de saúde com menor relação de vagas e médicos por habitante e com estrutura de serviços de saúde em condições de ofertar campo de prática suficiente e de qualidade para os alunos;

II - estabelecimento de novos parâmetros para a formação médica no País; e

III - promoção, nas regiões prioritárias do SUS, de aperfeiçoamento de médicos na área de atenção básica em saúde, mediante integração ensino-serviço, inclusive por meio de intercâmbio internacional.

7. Do ponto de vista jurídico, analisadas as disposições da Lei n. 12.871/2013, observa-se que as ações previstas se desdobram em três dimensões distintas: acadêmica, administrativa e de interiorização de cuidados médicos.

A acadêmica refere-se à oferta e estrutura dos cursos de medicina e ingresso na residência médica no País (arts. $3^{\circ} \S 7^{\circ} ; 4^{\circ}$ a $11 ; 22 ; 31$ ).

A dimensão de ordem administrativa envolve os termos de adesão ao chamamento público do SUS para autorização de novos cursos de medicina (art. $3^{\circ}$, caput e $\S \S 1^{\circ}$ a $6^{\circ}$ ); os Contratos Organizativos da Ação Pública Ensino-Saúde, a serem firmados com Estados e Municípios para reordenar a oferta de cursos e vagas de residência médica, e viabilizar a estrutura de serviços de saúde como campo de prática e integração ensinoserviço na Atenção Básica (art. 12); a criação e a transformação de funções no âmbito do Poder Executivo federal (art. 24); a autorização para que os Ministérios da Saúde e da Educação contratarem, mediante dispensa de licitação, instituição financeira federal para pagamento de bolsas (art. 25); a autorização para que órgãos federais concedam bolsas e adotem outras providências (art. 26); as demais medidas previstas nos arts. 27 a 33 .

A terceira dimensão tem por referência as estratégias de interiorização dos cuidados médicos, em regiões prioritárias para o Sistema Único de Saúde - SUS, inclui o Programa "Mais Médicos" para o Brasil e demais projetos e programas com a mesma finalidade (arts. 13 a 21; 23), como é o caso do Programa de Valorização do Profissional da Atenção Básica-PROVAB, instituído pela Portaria Interministerial n. 2.087, de 1/9/2011. 
8. Submetidas a diferentes regulamentações jurídicas, as três dimensões não se confundem, muito embora a formação médica envolva, necessariamente, o treinamento em serviço.

Enquanto a primeira diz respeito às questões de natureza acadêmica - sobre as quais incide a legislação educacional -, as demais concernem a diversos aspectos da oferta dos serviços públicos de saúde. Para estas, a legislação incidente é, sobretudo, de direito administrativo e, no que respeita à efetivação do direito à saúde, de direito sanitário.

Já dissemos que a legislação educacional compreende a lei de diretrizes e bases (Lei n. 9.394/1996), de competência da União (CF, art. 22, XXIV), as normas gerais editadas pela União, e a suplementação que venha a ser promovida pelos Estados e Distrito Federal (CF, art. 24, IX). De todas derivam atos regulatórios e interpretativos, emanados pelos diversos órgãos normativos dos sistemas de ensino (Ministério da Educação, Secretarias de Educação, Conselhos Estaduais e Nacional de Educação etc.). Os estatutos e regimentos universitários, que encontram fundamento no art. 207 da Constituição, também integram o conjunto.

A especificidade desse conjunto normativo decorre dos princípios constitucionais que orientam o oferecimento da educação e a atividade de ensino (CF, arts. 206 a 208) Adicionalmente, o princípio federativo e a autonomia universitária lhe impõem espaços próprios de vigência.

Isso significa que a Constituição Federal subtraiu as relações educacionais do direito administrativo comum, devido à sua índole e escopo. Como sistema orgânico, encerra regras e exceções (as disposições específicas da residência médica, previstas na Lei n. 6.932/1981, por exemplo); todo o seu conteúdo é, na íntegra, regulado de modo particular.

Ora, as mútuas implicações entre as ações do Programa, consideradas suas três dimensões, não são causa de derrogação do regime jurídico específico da área educacional, que é o que aqui nos interessa.

Aliás, como expresso no art. $1^{\circ}$ da Lei n. 12.871/2013, o objetivo do "Mais Médicos" é "formar recursos humanos na área médica para o SUS" (g. n.), sendo que a LDB legisla, justamente, para os processos formativos que se desenvolvem nas instituições de ensino (art. $1^{\text {o }}$, Lei n. 9.394/1996).

A Lei de Introdução às Normas do Direito Brasileiro (Lei n. 12.376/2010), ademais, estabelece que: “a lei nova, que estabeleça disposições gerais ou especiais a par das já existentes, não revoga nem modifica a lei anterior.” (art. $2^{\circ}, \S 2^{\circ}$ ). E estabelecendo 
exceções, deve ser interpretada restritivamente, especialmente quando restrinja direitos e garantias fundamentais reconhecidos e estabelecidos constitucionalmente. ${ }^{3}$

9. Parece evidente, porém, que a Lei n. 12.871/2013 pretendeu fundir as dimensões acadêmica e de organização de serviços da saúde, em favor da atuação prevalecente e centralizadora do Executivo federal na formação de médicos, na qualidade de recursos humanos para o SUS.

Aí se encontra o cerne da problematização ora levantada: ao estabelecer o controle da União sobre tal processo, o "Mais Médicos" incide em inconstitucionalidades e ilegalidades devido a não observância de competências estaduais e universitárias definidas pelo direito constitucional da educação e pela LDB.

O emprego deste procedimento vale-se de padrões de legitimação que não estão dentro do sistema jurídico, mas fora dele. Associada a atuação controladora do Executivo federal às metas de diminuição da carência de médicos e de fortalecimento da prestação de serviços de atenção básica em saúde, e, por via de consequência, à ideia de "democracia" - que traz implícita as noções de interesse público e de acesso universal e igualitário às ações e serviços de saúde, prevista no art. 196 da CF - o "Mais Médicos" apresenta um traço tido, axiologicamente, como positivo. A intenção final de controle total do processo - com seus potenciais problemas legais - é assim camuflada, alcançando-se, sem maiores percalços, o consenso social em torno das metas estatais.

É o que se verifica, por exemplo, na atribuição de bonificação, para fins de classificação em exames de ingresso na residência médica, a candidatos que tenham participado de ações de aperfeiçoamento na área da Atenção Básica (art. 22, § $2^{\circ}$, da Lei 12.871/2013). A medida apresenta flagrante desrespeito à autonomia universitária e às competências do poder público estadual, que financia, credencia e avalia os programas de residência médica de suas universidades.

3. A autonomia universitária e as novas regras da residência médica

10. O instituto da autonomia universitária, previsto no art. $207^{4}$ da Constituição Federal, distingue as universidades públicas no conjunto da Administração Indireta, por permitir-lhes a adoção dos modelos organizacionais e acadêmicos adequados à atividade acadêmica.

3 Nesse sentido, MAXIMILIANO, Carlos. Hermenêutica e aplicação do direito. 19. ed. Rio de Janeiro: Forense, 2001. p. 191. FERRAZ JÚNIOR, Tércio Sampaio. Introdução ao estudo do direito: técnica, decisão, dominação. 2. ed. São Paulo: Atlas, 1984. p. 295.

4 “Art. 207. As universidades gozam de autonomia didático-científica, administrativa e de gestão financeira e patrimonial, e obedecerão ao princípio de indissociabilidade entre ensino, pesquisa e extensão." 
É o que se encontra claramente expresso no art. 54, caput, da LDB: “As universidades mantidas pelo Poder Público gozarão, na forma da lei, de estatuto jurídico especial para atender às peculiaridades de sua estrutura, organização e financiamento pelo Poder Público, assim como dos seus planos de carreira e do regime jurídico do seu pessoal." (g. n.)

Num país de pouca e recente tradição acadêmica, como o Brasil, é baixo o grau de entendimento da autonomia como condição inerente às atividades universitárias de ensino e pesquisa, seja porque a ideia comum de autonomia está ligada mais à negação de qualquer limite ou vínculo do que às suas características essenciais (atuação normativa particular dentro de limites preestabelecidos), seja porque a atuação autônoma das instituições sempre se dará em face do Estado.

11. Como já tivemos oportunidade de destacar na doutrina, no Direito, o significado mais amplo e genérico de autonomia designa poder de autodeterminação, exprimindo a ideia de direção própria. Em termos mais precisos, "autonomia" indica a competência de autonormação, ou seja, a possibilidade de dar-se um ordenamento jurídico, o que consiste em poder funcional derivado, circunscrito ao peculiar interesse da entidade que o detém, e limitado pelo ordenamento geral em que se insere, sem o qual, ou fora do qual, não existiria. Este poder encera conteúdo político, uma vez que ser autônomo é dispor da prerrogativa de criar direito, ainda que em áreas de competência restritas e exclusivas. $^{5}$

Outro não é o sentido da expressão "autonomia" no art. 207 da Constituição Federal, que não significa soberania (é poder derivado) nem tampouco implica independência (a autonomia só existe dentro da lei), estando materialmente circunscrita ao que é próprio à universidade.

A autonomia, enfim, consiste em poder de autonormação exercitável dentro de determinados limites, sendo que as suas dimensões, em relação às universidades públicas e privadas, variam apenas em razão do regime jurídico a que se submetem. E isto porque a atuação autônoma de ambas sempre se dará em face do Estado: é este quem lhes outorga a autonomia, quem autoriza e avalia o seu funcionamento (CF, art. 209, II); credencia as instituições; avalia e reconhece os cursos oferecidos (CF, art. 206, VII; LDB, art. 46). Tanto é assim que o $\S 1^{\circ}$, do art. 46 da LDB, prevê a "suspensão temporária de prerrogativas de autonomia" como resultado de avaliação da instituição pelo respectivo sistema de ensino (ainda que o possa fazê-lo apenas mediante lei).

Sob este aspecto não se distingue a autonomia das instituições públicas e privadas. Tampouco se distingue em razão das dimensões materiais da outorga

Cf. RANIERI, Nina Beatriz Stocco. Autonomia universitária: as universidades públicas e a Constituição Federal de 1988. 2. ed. São Paulo: Imprensa Oficial, 2013. 
constitucional, voltadas ao ensino, à pesquisa e à extensão, e expressas nas vertentes didático-científica, administrativa e de gestão financeira e patrimonial.

12. A inclusão do princípio da autonomia universitária na ordem jurídica nacional não é nova. Já na Lei n. 4.024, de 20/12/1961, constava a previsão de atuação autônoma das universidades nas áreas didática, administrativa, financeira e disciplinar na forma dos seus estatutos (art. 80). Previsão assemelhada, porém mais restritiva, constou do já citado art. $3^{\circ}$, da Lei n. 5.540, de 28/11/1968: "As universidades gozarão de autonomia didático-científica, disciplinar, administrativa e financeira, que será exercida nos termos da lei e dos seus estatutos."

A partir da promulgação da Constituição Federal de 1988, a autonomia universitária passou a ser assegurada diretamente pelo seu art. 207, sem qualquer condicionamento à lei ordinária. Embora a Constituição Federal não tenha inovado a respeito da matéria e não tenha dado à universidade uma autonomia que ela não detinha, veio confirmar a autonomia existente, conferindo-lhe o "status" de regra constitucional.

Assim, ainda que o conteúdo jurídico desta autonomia continue tendo o mesmo significado, quer na lei ordinária, quer na Constituição Federal, a inserção no texto constitucional assegurou-lhe uma dimensão fundamentadora, integrativa, diretiva e limitativa, da qual decorrem importantes efeitos jurídicos:

a) o princípio da autonomia universitária se irradia por todo o sistema jurídico e deve ser interpretado à luz da Constituição Federal, em harmonia com os demais princípios e regras constitucionais, de maneira a alcançar a aplicação mais eficiente e em conformidade à finalidade para a qual foi instituído;

b) o conteúdo e os limites da autonomia universitária estão assinalados na Constituição Federal e nesses termos será exercida;

c) a norma do art. 207 é de igual hierarquia em relação às demais normas constitucionais;

d) a norma do art. 207 é de eficácia plena e aplicabilidade imediata, embora aceite regulamentação de caráter instrumental visando sua maior funcionalidade, expressas em normas gerais de educação, na lei de diretrizes e bases ou na legislação ordinária;

e) os limites impostos à autonomia das universidades decorrem diretamente da Constituição, sendo limites genéricos aqueles que decorrem dos princípios fundamentais do Estado brasileiro, dos direitos e garantias individuais, dos princípios educacionais expressos no art. 206 etc.; e limites específicos, os indicados no próprio art. 207. 
13. De tudo resulta que a norma do art. 207 assegura às universidades um mínimo intangível, garantia institucional sob proteção constitucional e, portanto, revestida da natureza de princípio informador do sistema jurídico, como observa Anna Cândida da Cunha Ferraz. ${ }^{6}$

As vertentes da autonomia universitária expressas no texto constitucional integram o mínimo intangível. Verdadeiros poderes enumerados, a autonomia didática e científica, a autonomia administrativa e a de gestão financeira e patrimonial são deferidos às universidades para que realizem sua missão de ensino, pesquisa e extensão de serviços à comunidade. Por esta razão, não aceitam definições, restrições ou limitações impostas pelo legislador infraconstitucional, inclusive o legislador constitucional estadual.

Isso, efetivamente, parece correto porque, conforme observou J. J. Gomes Canotilho, as garantias institucionais constitucionalmente protegidas, visam não tanto firmar, manter ou conservar certas instituições, mas impedir a sua submissão à discricionariedade dos órgãos estatais. ${ }^{7}$

Afirma o ilustre constitucionalista português: "A protecção das garantias institucionais aproxima-se, todavia, da protecção dos direitos fundamentais, quando se exige, em face das intervenções limitativas do legislador, a salvaguarda do "mínimo essencial' (núcleo essencial) das instituições." (g. n.) ${ }^{8}$

Não por acaso serviu-se o legislador constituinte de uma norma coercitiva para positivar aquele princípio, confirmando a posição superior da autonomia universitária no ordenamento jurídico: no que tange às condições de eficácia e aplicabilidade, o art. 207 da Constituição Federal expressa conduta certa e determinada, indica o conteúdo do direito e o respectivo sujeito.

Cuida-se de uma norma completa, que contém todos os elementos e requisitos necessários à sua incidência direta. É também uma norma de eficácia plena, que desde a sua edição produz, ou tem a possibilidade de produzir, todos os efeitos essenciais relativamente aos interesses que regula, ${ }^{9}$ o que de resto confirma-se pelo $\S 1^{\circ}$, do art. $5^{\circ}$, da Constituição Federal, pelas razões já expostas.

14. Ora, quando o Estado confere autonomia a um ente, impõe-se, voluntariamente, uma autolimitação, reconhecendo e adotando em seu sistema jurídico o

6 Cf. FERRAZ, Anna Cândida da Cunha. A autonomia universitária na Constituição de 05.10.1988. Revista da Procuradoria Geral do Estado de São Paulo, São Paulo, edição especial em comemoração aos 10 anos e Constituição Federal por ocasião do XXIV Congresso Nacional de Procuradores do Estado, set. 1998.

7 CANOTIlHO, Jose Joaquim Gomes. Direito constitucional e teoria da constituição. 6. ed. Coimbra: Almedina, 1993. p. 178.

8 CANOTILHO, Jose Joaquim Gomes. Direito constitucional ... cit., p. 522.

9 Cf. SILVA, José Afonso da. Aplicabilidade das normas constitucionais. 2. ed. rev. e atualizada. São Paulo: Revista dos Tribunais, 1982. 
direito produzido pelo ente ou órgão autônomo, que o declara tão obrigatório, dentro de sua esfera de incidência, quanto suas próprias leis, onde não as contravenha.

Conforme afirmado anteriormente, este é o desdobramento mais significativo da autonomia universitária: a universidade é uma entidade normativa. Produz direito; suas normas integram a ordem jurídica porque assim o determinou a norma fundamental do sistema. ${ }^{10}$

O reconhecimento da capacidade normativa dos estatutos universitários não é novo no nosso direito. Mesmo antes da inserção da garantia da autonomia universitária na Constituição Federal de 1988, o Supremo Tribunal Federal já havia se posicionado no sentido de que há um conteúdo normativo mínimo, residual, a ser resguardado aos estatutos universitários. ${ }^{11}$ A posição foi mantida, entendendo-se que as amplas e variadas prerrogativas concedidas pelo art. 207 seriam instrumentais em relação à autonomia didático-científica. ${ }^{12}$

15. Dentre as vertentes constitucionais da autonomia universitária, a autonomia didático-científica assegura a "direção própria" do ensino oferecido. Supõe o reconhecimento da competência da universidade para definir a relevância do conhecimento a ser transmitido, bem como sua forma de transmissão, corolários dos princípios da liberdade de ensino e do pluralismo de ideias e concepções pedagógicas, previstos nos incisos II e III, do art. 206 da Constituição Federal.

Decorrem logicamente dessa competência as capacidades de organizar o ensino, a pesquisa e as atividades de extensão, o que envolve a criação, a modificação e a extinção de cursos, a definição de currículos, o estabelecimento de critérios e normas de seleção e admissão de alunos, docentes e servidores etc., nos termos estatutários. Tais prerrogativas, sem prejuízo de outras, encontram-se atualmente discriminadas no art. 53, da Lei n. 9.394/1996. ${ }^{13}$

10 RANIERI, Nina Beatriz Stocco. Autonomia universitária: as universidades públicas e a Constituição Federal de 1988. 2. ed. São Paulo: Imprensa Oficial, 2013. p. 163/164.

11 Cf., dentre outros: Representação n. 1.170-RJ, rel. Min. Djaci Falcão, v.u., j. 07/10/1983, DJU 21/10/1983 (RTJ 111/107 e segs.); Recurso Extraordinário n. 100.769-SP, rel. Min. Rafael Mayer, j. 24/8/1984, DJU 21/9/1984 (RTJ 111/748 e segs.); Representação n. 1.454, rel. Min. Octávio Galloti, v.u., j. 24/3/1988, DJU. 20/5/1988 (RTJ 125/998).

12 Cf. Ação Direta de Inconstitucionalidade 51-RJ, rel. Min. Paulo Brossard, m.v., j. 25/10/89; DJU 17/9/1993 (RTJ 133/505 e segs.).

13 "Art. 53. No exercício de sua autonomia, são asseguradas às universidades, sem prejuízo de outras, as seguintes atribuições: I - criar, organizar e extinguir, em sua sede, cursos e programas de educação superior previstos nesta Lei, obedecendo às normas gerais da União e, quando for o caso, do respectivo sistema de ensino; II - fixar os currículos dos seus cursos e programas, observadas as diretrizes gerais pertinentes; III estabelecer planos, programas e projetos de pesquisa científica, produção artística e atividades de extensão; IV - fixar o número de vagas de acordo com a capacidade institucional e as exigências do seu meio; $\mathrm{V}$ - elaborar e reformar os seus estatutos e regimentos em consonância com as normas gerais atinentes; VI - conferir graus, diplomas e outros títulos; VII - firmar contratos, acordos e convênios; VIII - aprovar e 
Incluem-se entre elas a criação, organização e extinção pelas universidades, em sua sede, de cursos e programas de educação superior; a fixação de currículos de cursos e programas; o estabelecimento de planos, programas e projetos de pesquisa científica, produção artística e atividades de extensão; a fixação do número de vagas; a elaboração de estatutos; a atribuição de graus, expedição e registro de diplomas, celebração de contratos, acordos e convênios, aprovação e execução de planos, programas e projetos de investimentos; a administração de rendimentos conforme os dispositivos institucionais; a criação, expansão, modificação e extinção de cursos; a ampliação e diminuição de vagas; a elaboração de programas de cursos; a programação das pesquisas e das atividades de extensão; contratação e dispensa de professores; a definição de planos de carreira.

A prerrogativa de seleção de alunos, em todas as modalidades de cursos superiores previstas do art. 44 da LDB, encontra-se enunciada caso a caso no mesmo dispositivo, assim como a de fixação de vagas, prevista no Inciso IV, do art. 53 da LDB, cujo parágrafo único exige a disponibilidade de recursos financeiros para o exercício da autonomia universitária.

Isto posto, forçoso concluirmos que a fixação do número de vagas para cursos de graduação e programas de pós-graduação e especialização inclusive o de residência médica, é prerrogativa da própria universidade, com observância dos limites orçamentários e na forma de seus estatutos (Art. 207 da Constituição e arts. 53 e 54 da LDB).

A constatação também pode ser demonstrada pela previsão do $\S 1^{\circ}$, do art. 54, da LDB. Neste estão compreendidas atribuições concernentes à administração de pessoal e à gestão financeira, tais como a elaboração de regulamento funcional, em conformidade com as normas gerais concernentes; a aprovação e execução de planos, projetos e programas de investimentos referentes a obras, serviços e aquisições em geral, todos de acordo com os recursos alocados pelo respectivo mantenedor.

16. Neste ponto, cabe fazer algumas considerações sobre os programas de residência médica, definidos pelo art. $1^{\text {o }}$ da Lei n. 6.932/1981 como

modalidade de ensino de pós-graduação, destinada a médicos, sob a forma de cursos de especialização, caracterizada por treinamento em serviço, funcionando sob a responsabilidade de instituições de saúde, universitárias

executar planos, programas e projetos de investimentos referentes a obras, serviços e aquisições em geral, bem como administrar rendimentos conforme dispositivos institucionais; IX - administrar os rendimentos e deles dispor na forma prevista no ato de constituição, nas leis e nos respectivos estatutos; X - receber subvenções, doações, heranças, legados e cooperação financeira resultante de convênios com entidades públicas e privadas." 
ou não, sob a orientação de profissionais médicos de elevada qualificação ética e profissional.

Sendo curso de especialização - submetido, portanto, às regras da LDB - os programas de residência médica apresentam singularidades que os distinguem das demais especializações, devido à Lei n. 6.932/1981. Destaco quatro, a seguir examinadas.

A primeira diz respeito à necessidade de autorização dos programas, bem como de reconhecimento e renovação de reconhecimento, obrigações dispensadas para os demais cursos de pós-graduação lato sensu. ${ }^{14}$ Rigorosamente, tal previsão destina-se apenas às instituições não universitárias, à vista da prerrogativa de autonomia universitária consistente na criação de cursos e programas de educação superior (art. 53 da LDB).

A segunda especificidade da residência médica decorre da primeira: referese à substituição dos Conselhos de Educação (nacional e estaduais) pela CNRM, nas tarefas de credenciamento das instituições de saúde, supervisão e avaliação dos programas (Lei n. 6.932/1981 e Lei n. 12.871/2013).

Parece evidente que o papel atribuído à CNRM expressa a necessidade de que profissionais especializados realizem aquelas atividades, em benefício da qualidade do ensino médico exigida pelo art. 206, VII da Constituição Federal. Na Lei n. 6.932/1981, contudo, não há elementos suficientes ao reconhecimento do conteúdo básico das competências da CNRM em matéria de credenciamento de instituições de saúde e aprovação dos programas de treinamento médico.

Sendo assim, a regulação da residência médica pela CNRM compreendendo os atos de credenciamento e recredenciamento de instituições; autorização e reconhecimento de cursos - deve ser feita consoante os parâmetros da LDB, abaixo especificados.

Credenciamento e recredenciamento constituem atos administrativos unilaterais, vinculados, de natureza constitutiva e de competência da CNRM, que atestam, periodicamente, a qualificação acadêmica mínima para o funcionamento das instituições de ensino.

A autorização e o reconhecimento de cursos de ensino superior são atos administrativos unilaterais, vinculados, de competência do ministro da Educação exarados após deliberação da CNRM (art. $1^{\circ}, \S 2^{\circ}$, da Lei n. 6.932/1981 e arts. $7^{\circ}$, I e II, do Decreto n. 7.562/2011). Garantem, respectivamente, a possibilidade de funcionamento inicial do curso e, no caso da residência médica, a expedição de certificação válida em todo o território nacional (cf. art. 48, da LDB), inclusive para fins profissionais, junto

14 Cf. Resolução CNE n. 1, de 8 de junho de 2007, que estabelece normas para o funcionamento de cursos de pós-graduação lato sensu, no nível de especialização. Disponível em: < http://portal.mec.gov.br/cne/ arquivos/pdf/rces001_07.pdf>. 
ao Conselho Federal de Medicina (Lei n. 6.932/1981). Ambos conferem "qualificações" por prazo determinado, com a finalidade de garantir padrão de qualidade ao ensino, conforme exige o art. 206, VII, da Constituição Federal. ${ }^{15}$ São atos vinculados porque uma vez atendidos os requisitos estabelecidos pela lei, verificados mediante processo regular de avaliação (cf. "caput" do art. 46, da LDB), o Poder Executivo estará obrigado a autorizar e reconhecer cursos de educação superior. Distinguem-se os procedimentos quanto à natureza do ato. A autorização tem natureza constitutiva, posto atribuir à pessoa jurídica uma qualidade que até então não possuía, ainda que apresentasse os requisitos necessários para recebê-la. O reconhecimento, diversamente, tem natureza declaratória, porque exprime a declaração de algo já existente.

A natureza da atuação da CNRM, portanto, no credenciamento da instituição de saúde e na autorização e reconhecimento do programa (conforme Decreto n. 7.562/2011), é análoga à dos Conselhos de Educação, revestindo-se os atos administrativos que produz dos mesmos atributos e efeitos jurídicos daqueles emanados pelos demais Conselhos, tal como previstos na LDB. E tanto quanto aqueles Conselhos, sendo órgão de natureza e atribuições educacionais especializadas (integrado à estrutura do MEC), seu âmbito de atuação é delimitado pela autonomia das universidades e dos sistemas de ensino, no que couber.

17. Com a Lei do "Mais Médicos", a CNRM passou a ter outro encargo: instituir a avaliação específica anual dos programas de residência médica, a serem implementadas, exclusivamente no âmbito do sistema federal de ensino, pelo Instituto Nacional de Estudos e Pesquisas Educacionais Anísio Teixeira (INEP) (art. $9^{\circ}, \S \S 1^{\circ}$ e $2^{\circ}$ ). ${ }^{16}$ Nada é dito, na lei, em relação aos sistemas estaduais de ensino.

Ora, o art. 10, IV da LDB confere aos Estados competência para avaliar os cursos superiores oferecidos por suas instituições. Daí ser forçoso concluirmos que

15 O Decreto n. 7.562/2011 estabelece as consequências da não autorização para as instituições não universitárias: "Art. 16. O funcionamento de instituições ou a oferta de programas sem o devido ato autorizativo configura irregularidade administrativa, sem prejuízo dos efeitos da legislação civil e penal vigente. $\S 1^{\circ}$ Fica vedada a admissão de novos residentes pelas instituições na ausência de quaisquer dos atos autorizativos, sem prejuízo da aplicação das medidas cabíveis. $\S 2^{\circ}$ As instituições que oferecerem programas antes da devida autorização terão sobrestados os pedidos protocolizados perante o CNRM, devendo esta irregularidade ser considerada na análise final do ato autorizativo. $§ 3^{\circ}$ A Plenária determinará, motivadamente, como medida cautelar, a suspensão preventiva da admissão de novos residentes em programas ou instituições irregulares, visando evitar prejuízo a novos residentes. $\S 4^{\circ} \mathrm{Na}$ hipótese do $\S 3^{\circ}$, caberá recurso administrativo à Câmara Recursal, no prazo trinta dias."

16 “Art. $9^{\circ}$ É instituída a avaliação específica para curso de graduação em Medicina, a cada 2 (dois) anos, com instrumentos e métodos que avaliem conhecimentos, habilidades e atitudes, a ser implementada no prazo de 2 (dois) anos, conforme ato do Ministro de Estado da Educação. $\S 1^{\circ}$ É instituída avaliação específica anual para os Programas de Residência Médica, a ser implementada no prazo de 2 (dois) anos, pela CNRM. $\S 2^{\circ}$ As avaliações de que trata este artigo serão implementadas pelo Instituto Nacional de Estudos e Pesquisas Educacionais Anísio Teixeira (Inep), no âmbito do sistema federal de ensino.” 
a avaliação prevista no art. $9^{\circ}$ da Lei do "Mais Médicos" somente será aplicável aos sistemas estaduais mediante concordância expressa destes últimos e mediante convênio específico. Em outras palavras, a avaliação dos programas de residência médica oferecidos por universidades ou instituições de ensino não universitárias mantidas pelos Estados membros é competência própria desses mesmos Estados.

A terceira diferença entre a residência médica e os cursos de especialização em geral reside no fato de que, para os últimos, havia a possibilidade de oferta por instituições não educacionais, na forma da Resolução CNE n. 5, de 25/9/2008, suprimida em 2011 (Parecer CNE n. 3/2011). ${ }^{17}$

A Lei n. 6.932/1981 não abriu tal alternativa para a residência médica, sendo expressa quanto à exigência de oferta por “instituições de saúde, universitárias ou não". O sentido da expressão parece estar antes vinculado à obrigação das instituições realizarem ou não a pesquisa, conforme sejam "universitárias ou não", e não à possibilidade de o programa ser oferecido por instituição de saúde não educacional. É o que a interpretação extensiva da Lei n. 6.932/1981 e da LDB permitem concluir, especialmente em face do art. 52 desta última. ${ }^{18}$

A quarta singularidade é produto das alterações introduzidas pela Lei do "Mais Médicos". Concerne aos efeitos legais da residência médica no campo profissional devido à correspondência entre as áreas e subáreas dos programas e a certificação das especialidades médicas no País (art. $1^{\circ}, \S 3$ ). Disto resulta que os títulos de especialista regularmente emitidos são comprovantes hábeis junto ao sistema federal de ensino e ao Conselho Federal de Medicina (art. $6^{\circ}$ ).

Adicionalmente, a lei prevê garantias trabalhistas e previdenciárias para o médico residente (arts. $4^{\circ}$ e $5^{\circ}$ ), cuja vinculação ao programa dá-se por meio de contrato padrão de matrícula (art. $3^{\circ}$ ). Como podemos observar, há nítida preocupação com os direitos sociais do residente, conforme o art. $7^{\circ}$ da Constituição Federal; aliás, a competência para legislar sobre essa matéria é privativa da União (CF. art. 22, I e XXIII).

No conjunto, estas medidas demonstram que o legislador individualizou a residência médica como bem jurídico, cercando-a de garantias. Por todas essas razões, o

\footnotetext{
17 Disponível em: <http://portal.mec.gov.br/index.php?option=com_docman\&view=download\&alias=8232pcp003-11-pdf\&category_slug=junho-2011-pdf\&Itemid=30192>.

18 "Art. 52. As universidades são instituições pluridisciplinares de formação dos quadros profissionais de nível superior, de pesquisa, de extensão e de domínio e cultivo do saber humano, que se caracterizam por: I - produção intelectual institucionalizada mediante o estudo sistemático dos temas e problemas mais relevantes, tanto do ponto de vista científico e cultural, quanto regional e nacional; II - um terço do corpo docente, pelo menos, com titulação acadêmica de mestrado ou doutorado; III - um terço do corpo docente em regime de tempo integral."
} 
uso da denominação residência médica é exclusiva dos programas autorizados (art. $1^{\circ}, \S$ 2, da Lei n. 6.932/1981).

É importante atentamos para os limites dessa proteção: a Lei n. 6.932/1981 não trata de aspectos didático-científicos, mas da definição do âmbito de atuação da CNRM, dos direitos do médico residente e dos efeitos jurídicos da residência médica. ${ }^{19}$ Aqueles, são de competência das universidades.

Sendo assim, resta claro que os arts. 207 da Constituição Federal e o art. 53 da LDB constituem fundamentos suficientes para que as universidades públicas decidam acerca dos programas de residência médica que oferecem.

18. No mérito, fixado que os arts. 207 da Constituição Federal e o art. 53 da LDB constituem fundamentos suficientes para que as universidades estaduais decidam acerca dos programas de residência médica que oferece, o problema é saber se incidiriam sobre a sua atuação autônoma os seguintes dispositivos legais: a) Lei n. 12.871/2013 arts. $5^{\circ}$; $9^{\circ}$ e b) Diretrizes curriculares para o curso de Medicina (Res. CNE n. 3/2014) arts. $24, \S 2^{\circ}, 36$ e 37 .

No que se refere à Lei do "Mais Médicos”, será necessário, preliminarmente, distinguirmos entre as disposições exclusivas da lei (art. $9^{\circ}$ e 22), e as que são reproduzidas nas atuais DCN dos cursos de medicina (art. $5^{\circ}$ ). Isto porque, definidas pela Câmara de Educação Superior do CNE, para todo o conjunto de instituições de ensino superior do País (cf. art. $9^{\circ}$ da Lei n. 4.024, de 20/12/1961, com a redação da Lei n. 9.131, de 24/11/1995), as diretrizes curriculares são de observância obrigatória, para fim de reconhecimento dos cursos e consequente validade nacional dos diplomas (LDB, art. 48), desde que sigam a regra geral das competências educacionais. Ou seja, desde que estabeleçam princípios e fundamentos; caso contrário, aplicam-se apenas ao sistema federal de ensino (art. $9^{\circ}$, VII da LDB). ${ }^{20}$

18.1. - Dispõe o Art. $9^{\circ}, \S 1^{\circ}$ da Lei n. 12.871/2013: $\S 1^{\circ}$ É instituída avaliação específica anual para os Programas de Residência Médica, a ser implementada no prazo de 2 (dois) anos, pela CNRM.

19 A única previsão de natureza acadêmica presente na lei é a relativa aos efeitos do certificado de especialista para o sistema federal de ensino, sem menção aos sistemas estaduais. Outras disposições acadêmicas concernentes ao sistema federal podem ser encontradas na lei do Mais Médicos; é o caso da competência da CNRM para disciplinar a realização da residência médica em Medicina Geral de Família e Comunidade para determinados programas (art. $7^{\circ}, \S 2^{\circ}$ ) e para opinar acerca das alterações curriculares dos diversos programas (art. 11).

20 “Art. $1^{\circ}$ A presente Resolução institui as Diretrizes Curriculares Nacionais (DCNs) do Curso de Graduação em Medicina, a serem observadas na organização, desenvolvimento e avaliação do Curso de Medicina, no âmbito dos sistemas de ensino superior do país. Art. $2^{\circ}$ As DCNs do Curso de Graduação em Medicina estabelecem os princípios, os fundamentos e as finalidades da formação em Medicina." 
A regra da avaliação específica anual incide sobre as universidades estaduais por ter natureza diretivo basilar, mas não a sua implementação pelo CNRM (a menos que a dita implementação signifique estabelecimento de parâmetros e não realização). Conforme o art. 10, IV, da LDB, compete aos Estados avaliar os cursos superiores oferecidos por suas instituições.

18.2. - $\mathrm{O} \S 2^{\circ}$, do art. 22 da Lei n. 12.871/2013 refere-se à atribuição de bonificação aos participantes do PROVAB. Ora, a norma destina-se exclusivamente ao sistema federal de ensino. Não tem natureza diretivo-basilar, nem principiológica. Prevalece a autonomia universitária.

A previsão do art. 44, III da LDB é fundamento suficiente e cabal para garantir às universidades não integrantes do sistema federal a seleção dos médicos que participarão de seus programas de residência médica, na forma prevista em seus regulamentos, sem utilização compulsória da bonificação atribuída a candidatos que participaram do PROVAB. O mesmo se aplica à avaliação bienal do aluno de medicina, prevista no art. 36, das DCN do curso de medicina, adiante examinada.

18.3. - Os arts. $5^{\circ}$ da Lei n. 12.871/2013 e art. 37 das DCN estabelecem que os Programas de Residência Médica de que trata a Lei n. 6.932, de 7 de julho de 1981, ofertarão anualmente vagas equivalentes ao número de egressos dos cursos de graduação em Medicina do ano anterior.

Também aqui, as previsões, tanto na Lei do "Mais Médicos" quanto nas DCN, não tem natureza diretivo basilar ou de norma geral. Prevalece a autonomia universitária. Seu conteúdo não estabelece princípios e fundamentos, muito ao contrário: impõe uma conduta, a ser cumprida em prazo determinado, cuja natureza jurídica é de prerrogativa constitucional e legal da instituição de ensino universitário, mercê de sua autonomia, considerados os seus recursos financeiros e orçamentários (LDB, art. 53, parágrafo único e Constituição do Estado de São Paulo, art. 254, I). ${ }^{21}$

E embora as diretrizes curriculares sejam de observância obrigatória em todo o território nacional, a meta de universalização das vagas de residência médica até 2018 dirige-se exclusivamente ao sistema federal e, mesmo assim, com restrições, posto que invade a área de competência autônoma das universidades. É notório, no entanto, o baixo grau de autonomia das universidades federais, extremamente dependentes de recursos e do beneplácito do Ministro da Educação.

A previsão - em ambos os documentos - incorre em diversas inconstitucionalidades, por infringência à exigência de mérito para acesso ao ensino

\footnotetext{
$21 \quad \mathrm{O}$ art. 254, I exige que a autonomia da universidade seja exercida respeitando, nos termos do seu estatuto, a responsabilidade pública da instituição, observada a utilização dos recursos de forma a ampliar o atendimento à demanda social, tanto mediante cursos regulares quanto atividades de extensão.
} 
superior; por infringência à autonomia dos Estados membros e por infringência à autonomia universitária.

Do ponto de vista individual, está claro na Constituição Federal que o acesso aos níveis mais elevados do ensino está condicionado ao mérito (art. 208, V). Ora, a atribuição de direitos fundamentais envolve a correspondente atribuição de capacidade para o seu exercício, sob pena de não haver gozo desses direitos. E isto porque são conferidos em função de determinadas qualidades pré-fixadas pela Constituição, no caso da educação de nível superior, repita-se, a capacidade individual. Logo, para todos os que atendam a este requisito o Estado deve garantir acesso aos níveis mais elevados do ensino, da pesquisa e da criação artística.

No que consiste a garantia de acesso? Condicionada ao mérito, supõe seleção e, por via de consequência, classificação diante de um número finito de vagas. $\mathrm{O}$ ensino superior, diversamente do que ocorre em relação aos níveis fundamental e médio, não foi universalizado, não se destina a todos (CF, art. 208, I e II).

$\mathrm{Na}$ LDB a garantia de acesso equânime ao ensino superior expressa-se afirmativamente por meio da liberdade de seleção conferida às instituições de ensino, na forma do art. 44; liberdade limitada, evidentemente, pela noção de igualdade nos critérios de seleção. Qual a igualdade nos critérios de seleção, no caso da universalização da residência médica? Nesta situação, como em outras no mesmo campo, a exigência de equidade se impõe ligada ao princípio da igualdade de condições para o acesso e permanência na escola (CF, art. 206, I). Garanti-las é o dever do Estado e não mediante universalização de vagas.

Parece claro que a medida de universalização aventada no citado art. $5^{\circ}$ está diretamente relacionada ao condicionamento dos resultados da avaliação bienal do aluno de medicina, conforme ato do Ministro da Educação, à classificação para ingresso na residência médica $\left(\operatorname{art.} 9^{\circ}\right)$. Embora ainda não haja elementos que permitam avaliar a forma e o conteúdo de tal avaliação, a previsão reforça a ideia de facilitação para ingresso nos programas.

Neste ponto, fica patente o equívoco em que incide a Lei do "Mais Médicos" relativamente às vertentes acadêmica e de ampliação da oferta de médicos para o SUS. Como vimos, embora se relacionem, as esferas não se confundem; as interferências da meta de formação de recursos humanos para o SUS na área acadêmica são prejudiciais à qualidade do ensino e do treinamento médico.

A “democratização" do acesso ao ensino superior para a formação de recursos humanos para o SUS tampouco se confunde com o atendimento de carências da sociedade, embora as instituições superiores, em especial as públicas, devam contribuir para tanto.

18.4. - Finalmente, cumpre examinarmos o art. 36 das $\mathrm{DCN}$, relativa à avaliação obrigatória e específica do estudante do Curso de Graduação em Medicina, a 
cada 2 (dois) anos, como parte do processo de classificação para os exames dos programas de Residência Médica, credenciados pela Comissão Nacional de Residência Médica (CNRM), de âmbito nacional, a ser implantada pelo Instituto Nacional de Estudos e Pesquisas Educacionais Anísio Teixeira (INEP) para as Instituições de Educação Superior, no âmbito dos Sistemas de Ensino.

A previsão é nula, não opera nenhum efeito jurídico. Nem a Lei n. 6.932/1981, nem a Lei n. 12.871/2013, previram que os resultados da avaliação dos alunos dos cursos de medicina constituiriam parte do processo classificatório dos exames para a residência médica. A previsão, inova na ordem jurídica - inclusive quanto à atribuição ao INEP de competência para implantar a avaliação nacional no âmbito dos sistemas estaduais.

Ora, é cediço que a teor do art. 5, II, da Constituição Federal, "ninguém será obrigado a fazer ou deixar de fazer, senão em virtude de lei”; que por força do art. 37, "caput", da Constituição Federal, o princípio da legalidade vige para a Administração Pública segundo o cânone da estrita legalidade (para agir depende integralmente de previsão legal anterior que lhe faculte ou imponha o dever de atuar); e que o poder regulamentar do Executivo, previsto no art. 84, IV, da Constituição Federal, só pode ser exercido para a "fiel execução das leis".

Logo, a disposição do art. 36 das DCN é nula, por vício de ilegalidade, uma vez que, confrontada às disposições das Leis n. 6.932/1981, Lei n. 12.871/2013 e, principalmente, da LDB, estatui regras originárias e não secundárias.

Os limites do poder regulamentar estão obviamente relacionados com o fundamento jurídico que lhe deu causa, o que não se verificava em face do citado art. 36 . $\mathrm{O}$ vício, nesta hipótese, resolver-se-ia no campo da legalidade, ensejando até mesmo a sustação do ato normativo pelo Congresso Nacional, na forma do art. 49, V, da Constituição Federal. A jurisprudência, nesse sentido, é pacífica e há tempo se consolidou. ${ }^{22}$

\section{Conclusões}

A Lei n. 12.871/2013, para a consecução dos objetivos do Programa "Mais Médicos", pretende, entre outras ações, promover a reordenação da oferta de cursos de Medicina e de vagas para residência médica e estabelecer novos parâmetros para a formação de médicos. As medidas que constituem o objeto deste artigo, entretanto, não militam na direção desejada pela lei.

\footnotetext{
22 Cf. ADIN n. 392; STF, Tribunal Pleno; rel. Min. Marco Aurélio, em 20/6/91 (RDA 184:202-8): “Ação direta de inconstitucionalidade. Regulamento. Possível extravasamento revelado quando da edição do regulamento resolve-se no campo da legalidade (...).” Cf. ainda ADIN n. 1.553-DF; STF, Tribunal Pleno, rel. Min. Marco Aurélio (RTJ 164:532-43); ADIN N. 1.327/DF, STF, Tribunal Pleno, rel. Min. Neri da Silveira, v.u., DJ de 20/6/97; etc.
} 
A imposição da universalização das vagas da residência médica, a adoção nacional da bonificação conferida pelo PROVAB como elemento classificador nos exames de seleção para a residência médica e, da mesma forma, a dos resultados da avaliação dos cursos médicos, a ser conduzida nacionalmente pelo governo federal, não promovem o federalismo cooperativo que preside as ações do SUS.

A discriminação de competências dos entes federados e a autonomia das universidades, enunciadas pela Constituição Federal, não foram suficientes para diminuir o centralismo que preside o controle exercido pela União na avaliação de cursos, alunos e instituições, o que, por via de consequência, restringe a autonomia e articulação dos processos.

Em verdade, a postura intervencionista adotada, longe de sugerir uma atitude passiva por parte do Governo federal, indica o propósito de conduzir todo o processo de formação de recursos humanos para o SUS, a despeito de ser competência comum dos entes federados. Regular a educação superior e sua expansão constituem, portanto, atividades fortemente valorizadas pela União.

A elaboração de regulamentos que exorbitam os limites da função normativa administrativa - como ocorre em relação aos arts. 36 e 37 da Res. CNE n. 3/2014 - enseja questionamentos acerca da legalidade e da legitimidade do controle que exerce, o que não só o enfraquece como provoca um alto grau de incerteza relativamente ao referencial legal-administrativo assim inserido no sistema jurídico. Este procedimento desencadeia táticas defensivas, não cooperativas, por parte dos grupos afetados, e tende a relativizar o Direito em sua generalidade abstrata.

Nestas hipóteses, o problema da compatibilização autonomia/controle por via regulamentar é mais amplo: envolve matéria política, ligada à legitimidade de atuação, porque desconhece os preceitos legais e constitucionais hierarquicamente superiores assim como os valores e princípios que os informam. Negada esta condição, reafirma-se pela análise jurídica a constatação de que o Direito, no campo educacional, continua sendo utilizado como técnica de formalização e não como forma de concepção da sociedade, o que possibilita a preservação, na política e na prática educacionais, das características centralizadoras observadas no federalismo brasileiro.

Não parece que a estratégia adotada venha a induzir modificações significativas na formação de recursos humanos para o SUS ou para o sistema educacional, no que concerne à melhoria da qualidade do ensino e à ampliação do acesso, posto não alterar as condições de centralização e credencialismo, há muito presentes na legislação brasileira, e que, comprovadamente, não propiciaram aquelas condições.

São Paulo, novembro de 2015. 


\section{Referências}

BRASIL. Constituição da República Federativa do Brasil de 1988. Palácio do Planalto [da] Presidência da República, Brasília, DF, 1988. Disponível em: <http://www.planalto.gov.br/ ccivil_03/constituicao/constituicaocompilado.htm>.

BRASIL. Lei n. 9.394, de 20 de dezembro de 1996. Estabelece as diretrizes e bases da educação nacional. Palácio do Planalto [da] Presidência da República, Brasília, DF, 1996. Disponível em: $<$ http://www.planalto.gov.br/ccivil_03/leis/L9394.htm>.

BRASIL. Resolução CNE n. 1, de 8 de junho de 2007. Estabelece normas para o funcionamento de cursos de pós-graduação lato sensu, em nível de especialização. Ministério da Educação, Brasília, DF, 2007. Disponível em: <http://portal.mec.gov.br/cne/arquivos/pdf/rces001_07.pdf>.

CANOTILHO, Jose Joaquim Gomes. Direito constitucional e teoria da constituição. 6. ed. Coimbra: Almedina, 1993.

FERRAZ, Anna Cândida da Cunha. A autonomia universitária na Constituição de 05.10.1988. Revista da Procuradoria Geral do Estado de São Paulo, São Paulo, edição especial em comemoração aos 10 anos e Constituição Federal por ocasião do XXIV Congresso Nacional de Procuradores do Estado, set. 1998.

FERRAZ JÚNIOR, Tércio Sampaio. Introdução ao estudo do direito: técnica, decisão, dominação. 2. ed. São Paulo: Atlas, 1984.

MAXIMILIANO, Carlos. Hermenêutica e aplicação do direito. 19. ed. Rio de Janeiro: Forense, 2001.

RANIERI, Nina Beatriz Stocco. Autonomia universitária: as universidades públicas e a Constituição Federal de 1988. 2. ed. São Paulo: Imprensa Oficial, 2013.

. Educação superior, direito e Estado: na Lei de Diretrizes e Bases. São Paulo: EDUSP, 2000.

SILVA, José Afonso da. Aplicabilidade das normas constitucionais. 2. ed. rev. e atualizada. São Paulo: Revista dos Tribunais, 1982. 
